\title{
Historical Review and Cost-Effectiveness Assessment of the Programs to Eliminate Onchocerciasis and Trachoma in Mexico
}

\author{
Nadia A Fernández-Santos' \\ Francisco Gibert \\ Prado-Velasco ${ }^{2}$ \\ Dey Carol \\ Damián-González ${ }^{2}$ \\ Thomas R Unnasch ${ }^{3}$ \\ Mario A Rodríguez-Pérez (ID) \\ 'Instituto Politécnico Nacional, Centro \\ de Biotecnología Genómica, Laboratorio \\ de Biomedicina Molecular, Ciudad \\ Reynosa, Tamaulipas, México; ${ }^{2}$ Instituto \\ de Salud del Estado de Chiapas, \\ Programas de Tracoma y Oncocercosis \\ en Chiapas, Tuxtla Gutiérrez, Chiapas, \\ México; ${ }^{3} \mathrm{Global}$ Health Infectious \\ Disease Research Program, College of \\ Public Health, University of South Florida, \\ Tampa, FL, USA
}

\begin{abstract}
We present a historical review of two neglected tropical diseases (NTD), namely, onchocerciasis and trachoma, both which were successfully eliminated in Mexico. In addition, we present a cost-effectiveness assessment (CEA) demonstrating that these were worthwhile health interventions. Historically, an estimate of $\$ 310.68$ and $\$ 38.92$ per person were spent during the period of time the onchocerciasis and trachoma elimination programs operated, respectively.
\end{abstract}

Keywords: onchocerciasis, trachoma, assessments, Mexico, Chiapas, Oaxaca

\section{Introduction}

Trachoma and onchocerciasis are historically the leading and second most common avoidable causes of infectious blindness worldwide. Onchocerciasis is caused by infection with the parasite Onchocerca volvulus, a filariform nematode that is transmitted by the bite of black flies. Clinical signs and symptoms of onchocerciasis are characterized by itching, irritation, skin diseases, onchocercomas (nodules housing adult worms), adenopathies, and eye lesions, including irreversible blindness. ${ }^{1}$ Trachoma is a keratoconjunctivitis caused by repeated infections with the bacterium Chlamydia trachomatis. ${ }^{2,3}$

Here, we present a historical review of onchocerciasis and trachoma elimination programs in Mexico. The Mexican trachoma program operated for over 10 years whilst the Ministry of Health in conjunction with the Onchocerciasis Elimination Program in the Americas (OEPA) was operational for over 20 years. This longlasting partnership produced positive consequences in economic term, social, and otherwise as not only were the resources allocated to these programs used efficiently, but also eliminated the possibility of the disease expanding into new territories.

\section{Methods}

The historical review of the two programs relied primarily upon the dossiers provided to WHO by the Mexican higher health authorities. ${ }^{4}$ The dossier on onchocerciasis was submitted on November 21th, $2014^{4}$ and the trachoma dossier was submitted on April 22th, 2016. ${ }^{5}$ In addition, the Specific Program of Action for Onchocerciasis 2012-2018, ${ }^{6}$ published by the Sub Secretariat of Public Health of the Ministry of Health of Mexico, was consulted. Research articles on the status of onchocerciasis and
Correspondence: Mario A RodríguezPérez

Email drmarodriguez@hotmail.com 
trachoma were also consulted, and interviews with the brigades that participated in both programs were carried out. The cost-effectiveness analysis (CEA) used the methodology described in the CDC's published guidelines for economic assessments conducted in a public health. ${ }^{7,8}$

\section{The CEA of the Onchocerciasis Program}

Although the program of treatment with ivermectin concluded in 2011 (the post-treatment surveillance program was implemented from 2012 to 2015, and the post-elimination surveillance program from 2016 to present), a budget is still being provided, especially for advocacy and prevention activities. For example, brigades continue to monitor and remove "suspected masses of onchocerciasis" and performing parasitologic examinations. In addition, brigades have supported other important programs such as deworming and, there are currently underway, activities against the Covid-19 pandemic. ${ }^{4}$ The first metric is the number and cost (\$1.5) of ivermectin pills consumed annually (Figure 1) and the second metric is the total expenditure from 1994 to 2020 (Table 1). In particular, for the Chiapas onchocerciasis program, the largest expense was for the payment of brigades $(81.31 \%$ of the total budget) as shown in Table 2. OEPA also allocated resources to support the Mexican onchocerciasis program as shown in Table $1 .{ }^{4}$ A projection can be made of what had been spent since the program began, namely, from 1994 to 2011 (Table 1). From 1994 to 2003, \$15,095,770.00 were provided by the States and $\$ 7,359,450.00$ by MDP which made a sub-total of $\$ 22,455,220.00$. From 2004 to 2012, $\$ 1,006,416.00$ was provided by OEPA, $\$ 17,680,171.00$ by the States and $\$ 9,624,515.00$ by MDP which made a subtotal of $\$ 28,311,102.00$. From 2013 to 2020, $\$ 96,180.00$ were provided by OEPA and $\$ 6,648,168.00$ by the States which made a sub-total of $\$ 6,744,348.00$ (Table 1). Overall, the total cost of the national onchocerciasis program was $\$ 57,510,669.73$ (Table 1).

\section{The CEA of the Trachoma Program}

The annual budget allocated the Chiapas Health Services from 2004 to 2020 to the trachoma program was, on average, of $\$ 347,404.63$ (Table 3). The program was administered by the Health Jurisdiction II of the municipality of San Cristobal de las Casas (SJII-SCC); 26, Communities from five municipalities (Chanal, Huixtán, Oxchuc, Tenejapa, and San Juan Cancuc) with a total population of 363,537 inhabitants were served. As of 2016, the allocated budget was no longer eliminating trachoma disease, as this goal was achieved almost by $100 \%$ during 2015 ; the goal shifted to preventing

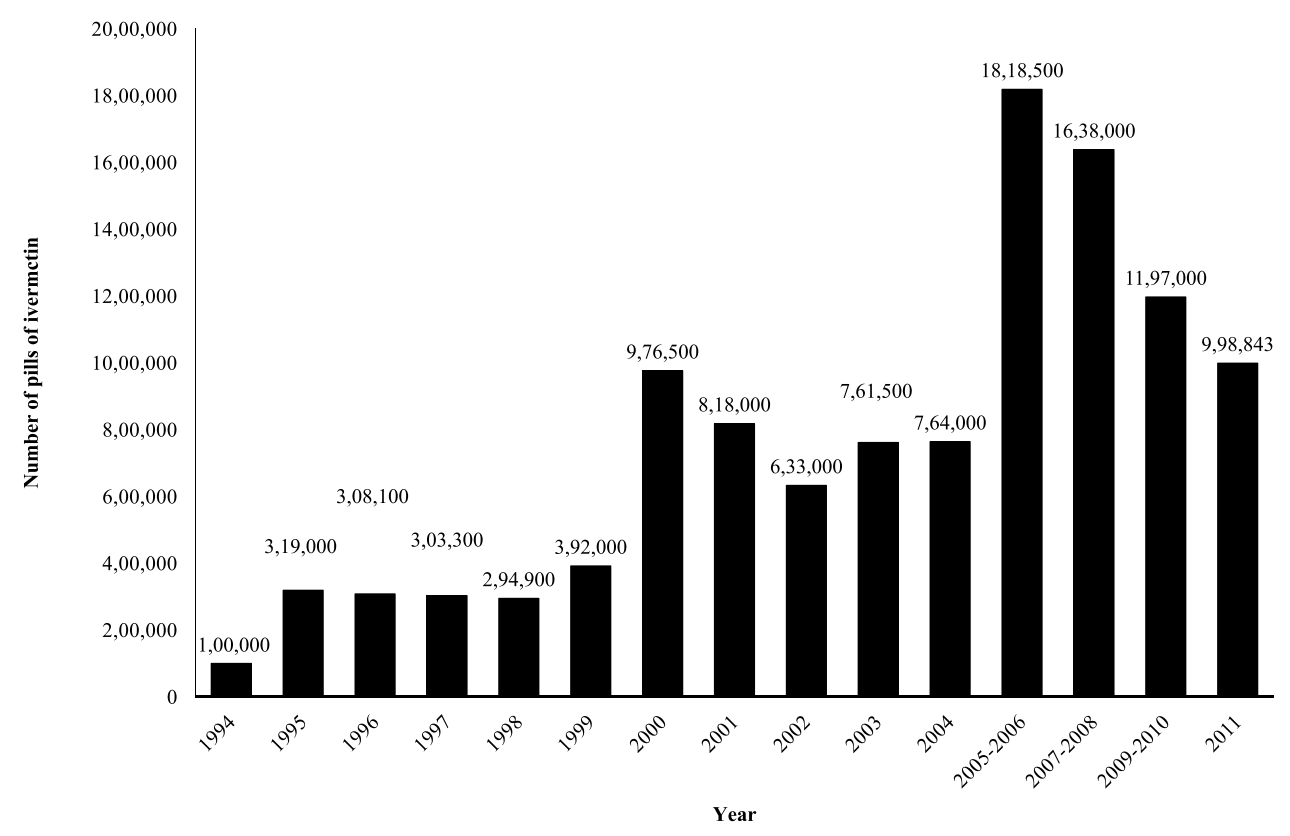

Figure I Doses of ivermectin provided by the Mectizan donation program to the onchocerciasis elimination program of Mexico from I994 through $20 \mathrm{II}$. Data were provided by the Secretariate of Health, Mexico, the ISECH, ${ }^{4}$ and the Chiapas Ministry of Health. In 2006, the 19th anniversary of the Mectizan Donation Program was held, which reported that by that date, the program would had donated around 1.8 billion tablets worldwide at a cost of approximately $\$ 2.7$ billion. Using these data, it can be calculated the cost for each ivermectin pill (ie, \$1.5): ${ }^{4,6}$ From 1994 through 201 I, II,322,643 ivermectin pills had been provided by the MDP to Mexico. From these, $4,906,300$ pills were known to had been consumed from 1994 to 2003 . Thus, 4,906,300 pills times $\$ 1.5$ made $\$ 7,359,450.00$. From 2004 to $201 \mathrm{I}, 6,416,343$ ivermectin pills were consumed which made $\$ 9,624,514.50(6,416,343$ pills $\times \$ 1.5)$. 
Table I Budget in USD Allocated by OEPA, OEPM, and MDP to the Onchocerciasis Program of Mexico from 1994 Through 2020

\begin{tabular}{|c|c|c|c|c|}
\hline Year & OEPA & OEPM & MDP & Total \\
\hline 1994 & & I,509,577 & 150,000 & I,659,577 \\
\hline 1995 & & I,509,577 & 478,500 & I,988,077 \\
\hline 1996 & & I,509,577 & 462,150 & I,97I,727 \\
\hline 1997 & & $\mathrm{I}, 509,577$ & 454,950 & $1,964,527$ \\
\hline 1998 & & I,509,577 & 442,350 & I,95I,927 \\
\hline 1999 & & $\mathrm{I}, 509,577$ & 588,000 & $2,097,577$ \\
\hline 2000 & & $1,509,577$ & $\mathrm{I}, 464,750$ & $2,974,327$ \\
\hline 2001 & & I,509,577 & $1,227,000$ & $2,736,577$ \\
\hline 2002 & & $\mathrm{I}, 509,577$ & 949,500 & $2,459,077$ \\
\hline 2003 & & I,509,577 & $\mathrm{I}, \mathrm{I} 42,250$ & $2,65 I, 827$ \\
\hline 2004 & 53,168 & I,509,577 & $I, I 46,000$ & $2,708,745$ \\
\hline 2005 & 89,097 & I,626,878 & $2,727,750$ & $4,443,725$ \\
\hline 2006 & 166,315 & $1,716,049$ & & $\mathrm{I}, 882,364$ \\
\hline 2007 & 127,419 & $1,749,164$ & $2,457,000$ & $4,333,583$ \\
\hline 2008 & 197,896 & $|, 662,83|$ & & $\mathrm{I}, 860,727$ \\
\hline 2009 & 83,479 & $2,210,546$ & $\mathrm{I}, 795,500$ & $4,089,525$ \\
\hline 2010 & 110,865 & $2,319,64 \mid$ & & $2,430,506$ \\
\hline 2011 & 48,970 & $2,219,915$ & $1,498,265$ & $3,767,150$ \\
\hline 2012 & 129,207 & $2,665,570$ & & $2,794,777$ \\
\hline 2013 & 96,180 & $2,590,316$ & & $2,686,496$ \\
\hline 2014 & & $766,786.4 I$ & & 766,786 \\
\hline 2015 & & $642,321.83$ & & 642,322 \\
\hline 2016 & & $545,825.42$ & & 545,825 \\
\hline 2017 & & $539,531.86$ & & 539,532 \\
\hline 2018 & & 530,257 & & 530,257 \\
\hline 2019 & & $529,703.54$ & & 529,704 \\
\hline 2020 & & $503,425.67$ & & 503,426 \\
\hline Total & $I, 102,596$ & $39,424,108.73$ & $16,983,965$ & $57,510,670$ \\
\hline
\end{tabular}

Notes: Data from Ministry of Health, Mexico, ISECH, OEPA, MDP, ${ }^{4,6,20,32}$ and Chiapas Ministry of Health.

Table 2 Percentage of the Budget per Item Allocated to the Onchocerciasis Program in the State of Chiapas

\begin{tabular}{|l|r|c|}
\hline Item & \multicolumn{1}{|c|}{ Budget } & Percentage per Item \\
\hline Administrative materials & $1,719.64$ & 0.34 \\
Vehicles parts & $11,207.80$ & 2.23 \\
Vehicles fuel & $39,427.59$ & 7.83 \\
Vehicles repairs & $9,180.65$ & 1.82 \\
Brigades salary and viatics & $409,378.08$ & 81.31 \\
Brigades transportation & $32,576.5 \mathrm{I}$ & 6.47 \\
Total & $503,490.28$ & 100.00 \\
\hline
\end{tabular}

Notes: Data from the Ministry of Health, México, ISECH, ${ }^{4}$ and the Chiapas Ministry of Health.

further trachoma cases. The total cost, considering the budget allocated by PAHO ( $\$ 12,000.00$ during 2015) and for the national trachoma program was $\$ 5,905,878.70$ (Table 3). The largest expenditure (63.68\%) was for brigade salaries (Table 4).
Table 3 Historical Budget in USD Allocated the Trachoma Program in the State of Chiapas

\begin{tabular}{|c|c|}
\hline Year & Budget \\
\hline 2004 & $\$ 427,553.99$ \\
2005 & $\$ 454,502.36$ \\
2006 & $\$ 446,934.32$ \\
2007 & $\$ 442,837.77$ \\
2008 & $\$ 349,339.12$ \\
2010 & $\$ 369,935.69$ \\
2011 & $\$ 391,520.26$ \\
2012 & $\$ 346,582.50$ \\
2013 & $\$ 372,790.13$ \\
2014 & $\$ 369,370.03$ \\
2015 & $\$ 363,172.77$ \\
2016 & $\$ 316,816.32$ \\
2017 & $\$ 258,519.10$ \\
2018 & $\$ 255,538.28$ \\
2019 & $\$ 251,145.43$ \\
2020 & $\$ 250,883.30$ \\
Total & $\$ 238,437.32$ \\
\hline
\end{tabular}

Note: Data from PEPCT, Ministry of Health, Mexico, ${ }^{5,40}$ and Chiapas Ministry of Health.

Table 4 Percentage of the Budget Allocated to the Trachoma Program in the State of Chiapas

\begin{tabular}{|l|c|c|}
\hline Item & Budget & Percentage per Item \\
\hline Brigades salary & $\$ 162,785.34$ & 63.68 \\
Brigades viatics & $\$ 49,791.11$ & 19.47 \\
Vehicle fuel & $\$ 43,051.06$ & 16.84 \\
Total & $\$ 255,627.52$ & 99.99 \\
\hline
\end{tabular}

Note: Data from PEPCT, Ministry of Health, Mexico, ${ }^{5,40}$ and Chiapas Ministry of Health.

\section{Results}

\section{A Historical Review of Onchocerciasis in Mexico}

In 1935, the Department of Public Health established onchocerciasis as a disease of national interest ("a filariasis considered in the Federal Health Code as a communicable disease belongs to the Federal Health Authority, the campaign against the disease") and developed the regulations of the campaign against onchocerciasis. These were published in the Official Journal of the Federation on April 13th, 1935, which established the legal, health, and control measures deemed necessary at the time. ${ }^{9}$ Thus, the onchocerciasis control program was the oldest public health program in Mexico.

At the start of the program, three onchocerciasis foci in Mexico were identified. Two were in the state of Chiapas 
(one in the Northern in the Chamula area and the other one in the Southern in the Soconusco area). The third focus was located in Oaxaca. The three foci had similar characteristics. They shared a common vector (Simulium ochraceum s.l.), that was found between 500 and 1500 meters above sea level, in areas with a humid-warm climate, abundant seasonal rains, and lush vegetation. The foci were also in rural areas that were difficult to access and home to indigenous populations mainly dedicated to the cultivation of coffee. ${ }^{10-17}$

The Mexican effort to eliminate onchocerciasis received a big boost with the formation of the Onchocerciasis Elimination Program for the Americas (OEPA). OEPA was established in 1992. It was initially coordinated by the River Blindness Foundation (RBF). The RBF merged with the Carter Center in 1995, and since then OEPA has been administered by the Carter Center through the Global Program 2000. In the first years, OEPA was operating it set no concrete goals, but in 2008 OEPA declared that its goals would be to eliminate new eye morbidity attributable to the onchocerciasis in all endemic foci by 2012, to halt the transmission of the 13 endemic foci in the region by 2012 (last year of treatment distribution), and to complete the three-year phase of post-treatment epidemiological surveillance by $2015 .{ }^{1}$ OEPA proposed to accomplish these goals by implementing safe and locally supported programs for the distribution of ivermectin every six months (two rounds of treatment per year) to the eligible population residing in the 1950 endemic communities of onchocerciasis in the region. OEPA received technical assistance and funding from public and private sources, including the Carter Center, the Lions Club, the US Centers for Disease Control and Prevention (CDC), WHO/PAHO, the Bill and Melinda Gates Foundation, the Mectizán Donation Program (MDP), and Merck Sharp \& Dohme (MSD), among others. As part of their strategic plan, stakeholders in OEPA convened international meetings on a periodic basis to review progress towards elimination in Latin American countries where onchocerciasis existed. ${ }^{1,9,18}$

In Mexico, the national program began its path to elimination by selecting a group of communities in each of the three foci to serve as sentinels. These were selected through data collected as part of prior detailed epidemiological assessments in all communities in the three foci. This procedure was named "in-depth epidemiological assessment" (IdEP). This procedure provided a parasitologic, serologic, ophthalmologic, and entomologic evaluation of all communities surveyed. ${ }^{19-23}$

\section{Treatment Strategies of the Mexican Program}

In the face of a lack of a safe and effective drug to treat $O$. volvulus infection, the first campaigns for the control of onchocerciasis focused two strategies. The first was vector control, using insecticides to reduce the abundant vector populations. The second was reduction of the adult parasite population by nodulectomy campaigns (removal of the nodules that house adult worms) which were implemented to reduce the most severe cases of the disease. ${ }^{24}$ Between 1947 and 1949, diclerholyceryltricloroethane (DDT) and diethylcarbamazine (DEC) ${ }^{24,25}$ were first used to control vector populations, and treat all patients affected by the parasite $O$. volvulus, respectively. ${ }^{26}$ In the mid-1980s, ivermectin was shown to be a safe and highly effective microfilaricide for the treatment of onchocerciasis. In 1992 following the agreements reached by the XXV Assembly of Directors of the PAHO and the OEPA, systematic implementation of ivermectin began. ${ }^{19,22}$

In Mexico, the onchocerciasis program established two concepts for treatment; namely, "onchocerciasis case" targeting individuals who were at some point positively diagnosed for onchocerciasis. The "re-infected case" was defined as a previously infected person who, having been discharged and deemed to have been cured, subsequently had a positive reaction from a Mazzotti (a test that was performed four times on previously cured individuals to ensure sure the infection had disappeared). ${ }^{27-29}$

Treatment with ivermectin in the focus of Oaxaca began in 1989 covering the entire eligible population. However, this was not the case in the two endemic foci of Chiapas, where only the onchocerciasis cases were treated. ${ }^{29}$ In 1993, the onchocerciasis national program changed from a control to an elimination strategy, and community wide treatments began in the two Chiapas foci. In 1994, mass treatment with ivermectin was implemented only in hyper- and mesoendemic communities; it was also decided to treat only $25 \%$ of the eligible population in the hypoendemic communities. In 1995, this was increased to $40 \%$ of the eligible population and in 1998 , the goal of treating the $100 \%$ of the eligible population in all communities was set, regardless of their level of endemicity. ${ }^{4,20,30,31}$

In the Southern Chiapas focus, progress towards elimination was slow relative to the other two foci, a result of the size of the at risk population and relative intensity of transmission. Modeling studies suggested that under a scheme of 
twice per year treatments covering a minimum of $85 \%$ of the eligible population, elimination of the disease would be achieved over a period of between 12 and 14 years. As a result, OEPA and the national program decided to look at alternatives that would allow it to speed up the process and reduce treatment time to achieve the goal of elimination by 2012. It was decided that in this focus, treatments should be increased to four times per year. In 2003, the program initiated this special intervention in 37 hyperendemic communities and 12 selected mesoendemic communities; one more community was added in 2004. In 2009, based on positive data obtained in the initial communities receiving four times per year treatment, the program decided to include 113 more communities in this scheme. ${ }^{4,20,21}$

\section{The Path to Elimination}

Table 5 summarizes the interim data on the elimination program showing the decrease in entomological and epidemiological indicators over the course of the elimination program. ${ }^{20}$ The smallest of the historically endemic foci, northern Chiapas, was the first in which the interruption of transmission of $O$. volvulus was reported to have been achieved after exhaustive clinical, epidemiological, and entomological studies. ${ }^{20,32}$ This occurred in 2007, after 10 years of twice per year treatment with ivermectin of the communities at risk..$^{20,24,25,32}$ Northern Chiapas was followed in 2008 by the second largest focus in Mexico, Oaxaca (after 13 years of twice per year treatment); ${ }^{20,32}$ and, finally, by the largest focus, Southern Chiapas, in 2011 (after 17 years of annual and quarterly semi-treatments aimed at accelerating the halting of transmission). ${ }^{20}$ The date when focal elimination was achieved for each focus, was 2010, 2011, and 2014, respectively, corresponding to when the last entomologic survey of the post-treatment surveillance period was conducted. ${ }^{20}$ In 2015, the WHO verified the elimination of onchocerciasis from Mexico.

\section{The CEA of the Onchocerciasis Program}

We estimated that from the period from 1994 to 2000 there was, on average, 185,113 people at risk each year in Oaxaca and Chiapas. If the $\$ 57,510,669.73$ spent on the program (Table 1) were divided into 185,113 people an expenditure of $\$ 310.68$ per person was spent throughout the time (26 years) when the program had been operating. $^{33}$

\section{A Historical Review of Trachoma in Mexico}

Upon the arrival of Europeans in the Americas, trachoma was described as the existence of conjunctival granulations

Table 5 The Epidemiological Situation in the Three Onchocerciasis Endemic Foci in Mexico

\begin{tabular}{|c|c|c|c|c|}
\hline Focus/Year of Evaluation & $\begin{array}{l}\text { No. of "New" } \\
\text { Clinical Cases* }\end{array}$ & $\begin{array}{c}\text { No. of Individuals } \\
\text { at Risk }\end{array}$ & $\begin{array}{c}\text { Prevalence of Infective } \\
\text { Flies/ 2,000 }\end{array}$ & $\begin{array}{c}\text { Seasonal Transmission } \\
\text { Potential }^{\pi}\end{array}$ \\
\hline Northern Chiapas'/ 1993 & 13 & 15,539 & ND & ND \\
\hline Northern Chiapas'/ 1999-200I & 0 & 21,572 & $0.4(0.0-0.90)$ & $1.0(0.0-2.2)$ \\
\hline Northern Chiapas'/ 2005 & 0 & 7,092 & $0(0.09)$ & $0(0.05)$ \\
\hline Northern Chiapas 2007 & 4 & & & $0(0-1.3)$ \\
\hline Northern Chiapas ${ }^{\#} / 2010$ & 0 & $7125^{\&}$ & $0(0.3)$ & $0(4.4)$ \\
\hline Southern Chiapas²/ 1993-199| & 904 & 190,744 & $1.8(0.9-3.3)^{8}$ & $95.2^{8}$ \\
\hline Southern Chiapas²/ 1999-200I & 274 & 219,923 & $0.4(0.2-0.90)$ & $1.2(0.6-2.8)$ \\
\hline Southern Chiapas 2008 & 6 & & & $0(0-1.2)$ \\
\hline Southern Chiapas²/ 201I & 9 & II 4,024 & $0(0.06)$ & $0(1.0)$ \\
\hline Southern Chiapas ${ }^{\# / 2014}$ & 0 & $117,825^{\&}$ & $0(0.1)$ & $0(1.7)$ \\
\hline Oaxaca $^{3} / 1993$ & 316 & 64,426 & ND & ND \\
\hline $\mathrm{Oaxaca}^{3} /$ |999-200| & 1 & 65,447 & $0.7(0.4-1.2)$ & $3.2(1.9-5.8)$ \\
\hline $\mathrm{Oaxaca}^{3} / 2008$ & 0 & 44,919 & $0(0.07)$ & $0(1.9)$ \\
\hline Oaxaca ${ }^{\# / 201 I}$ & 0 & $44,919^{8}$ & $0(0.1)$ & $0(1.2)$ \\
\hline Oaxaca ${ }^{\#} / 2011$ & 8 & & & $0(0-1.7)$ \\
\hline
\end{tabular}

Notes: Reproduced from Rodríguez-Pérez MA, Fernández-Santos NA, Orozco-Algarra ME, et al. Elimination of onchocerciasis from Mexico. PLoS Negl Trop Dis. 20I5;9(7): e0003922. ${ }^{20}$ Copyright: @ 2015 Rodríguez-Pérez et al. Creative Commons Attribution license (CC BY); https://creativecommons.org/licenses/by/4.0/legalcode. Permission to re-use the content was granted by PLOS Neglected Tropical Diseases Editorial Office Ltd. Geographical extension (2000): ${ }^{1} \mathrm{I}, \mathrm{I72} .10 \mathrm{~km} 2{ }^{2}{ }^{13}, 90 \mathrm{I} .3 \mathrm{~km} 2 ;{ }^{3} 4,250,0 \mathrm{~km} 2$. * “New" clinical onchocerciasis cases were defined as those individuals diagnosed positive by Mazzotti reaction, nodules, or skin biopsies ('snips') for the first time. "The upper value represents point estimate and the lower value in parentheses represents the $95 \%$-confidence interval. When the point estimate was 0 only the upper limit of confidence interval is presented. ${ }^{\&}$ Las Golondrinas, ${ }^{21}{ }^{\#}$ The study by Rodríguez-Pérez et al, ${ }^{20}$ and population no longer at risk of infection. 
among Mexico's population. The prevalence of trachoma in Mexico was essentially unknown until the late 19th century. By 1896, the presence of trachoma in Mexico was discussed at the Second Pan American Medical Congress when the Hospital of Ophthalmology, reported having historic records of 42,000 cases of trachoma from indigenous people of the Toluca Valley and Texcoco since the hospital's founding in 1876. In 1906, Lorenzo Chávez also noted that overcrowded conditions, lack of hygiene, and basic sanitation favored the transmission of the disease. ${ }^{34-36}$ Solórzano Morfín documented the presence of trachoma among Veracruz military and civilians. ${ }^{37,38}$ In addition, Dan M. Vélez et al reported the existence of trachoma in the civilian, migrant, and indigenous populations in 1918 and 1923. After the existence of this condition was demonstrated in Mexico and an increase in trachoma was related to the presence of Asian immigrants, trachoma was listed in the Official Journal of the Federation (DOF) and the Health Code, as an infectivecontagious disease in 1927..$^{37-39}$

From 1944 to 1961, there were no reports concerning the epidemiology of trachoma, coinciding with the structural changes that occurred in the health system, specifically the merger of the Department of Health and the Secretariate of Social Assistance in 1943. This period coincided with the construction of the network of hospitals throughout the Mexican Republic which had been suspended since 1910. This was promoted by Gustavo Baz, Prime Minister of Health and Assistance in Mexico. The advent of decentralized medical institutions such as the Children's Hospital of Mexico (1943), the National Institute of Cardiology (1944), and the Hospital of Nutrition Diseases (1944), among others, resulted in a paucity of centralized data on trachoma. Thus it was not until 1962 that Javier Torroella was the first to study and initiate actions against trachoma in the highlands of the Chiapas state. ${ }^{37-39}$ This was the only known historic focus of trachoma as a cause of infectious blindness in Mexico. Trachoma was found to be endemic in five municipalities, with communities that in the 1980 s showed rates of over $25 \%$ of follicular trachomatous inflammation (TF) in children under 10 years of age and $100 \%$ of scar trachoma (ie, trachomatous scarring [TS] and trachomatous trichiasis [TT]) in the adult population. . $^{5,40}$

Evidence of the conditions and goals achieved for the elimination of trachoma as a public health problem in Mexico, particularly in the state of Chiapas, has been documented by the contributions of multi-sectorial work, under the leadership of the National Health System in that State. In 1996, the WHO formed the Alliance for the Global Elimination of Blinding Trachoma, ${ }^{37,39,41}$ guiding the implementation of specific and special strategies against the disease in endemic countries. Even though trachoma is a preventable disease, is the leading cause of infectious blindness worldwide. Trachoma affects populations where conditions of extreme poverty and social, cultural, and economic marginalization favor transmission, most often in children under the age of ten. ${ }^{42-45}$

Several government institutions implemented a strategy for the prevention and treatment of this disease that for several years had been afflicting the most vulnerable people in Chiapas. This approach was successful, with benefits ranging from the disease prevention and improvements in the social conditions of the affected population. This was accomplished at a low cost, as the allocated resources were used efficiently and responsibly. ${ }^{37,43}$

The Institute of Health of the State of Chiapas implemented the Federal programs for the population through ten health areas called Health Jurisdictions; each of these jurisdictions included a variable number of municipalities. The five historic endemic municipalities for trachoma were located in the HJII-SCC. The trachoma program was coordinated at the national level by the National Center for Preventive Programs and Disease Control (CENAPRECE) of the Mexican Ministry of Health; in Chiapas. The State Secretariate of Health and its Directorate of Public Health, through the Sub-Direction and the Department of Preventive Programs, led the State Coordination of the Trachoma Prevention and Control Program (PEPCT as in Spanish acronym); the PEPCT was subscribed to the HJII-SCC and it was directly dependent on the trachoma brigade teams. In the five municipalities considered endemic, each had their own trachoma brigade team. These municipal teams were run by a brigade doctor who coordinated the work of their nursing technicians, health technicians, and multipurpose teams. The municipality, therefore, was the operational administrative unit in Chiapas through which the actions of prevention and control of trachoma were implemented. ${ }^{37,44}$

Epidemiological studies of trachoma in the endemic area in Chiapas that were conducted from 1965 to 2017 showed progressive decline in prevalence. The prevention of trachoma-related pathology was further strengthened through the sanitation programs conducted by the aforementioned institutions. Particularly in Chiapas, the installation of the program included a series of strategies and 
measures for the promotion of health (such as correct washing of the face and hands), in addition to population health examinations, the dispensing of antibiotics for the treatment of the disease, and surgeries. ${ }^{40-52}$

From 2004 to 2020, the Ministry of Health of Chiapas implemented an institutional trachoma program, with the allocation of a budget of $\$ 347,404.63$ per year. The exception to this was in 2015, when the typical annual appropriation was increased by $\$ 12,593.67$ by a supplemental allocation. Since the creation of the PEPCT in 2004, the Health Institute of the State of Chiapas (ISECH as in Spanish acronym) has overseen the training and maintenance of brigades exclusively focused on trachoma surveillance, prevention, and control activities in known areas in the State highlands. ${ }^{5,40}$

The operational strategic approach prior to 2001 consisted of randomly selecting communities from the five municipalities, searching for active cases of trachoma in all its phases, sensitizing patients for surgery, administration of azithromycin, promotion, health education through video projection, photo exposure, triptychs, and demonstration of face washing. In 2007, an agreement was established between the different institutions in response to a call issued by the Mexican Association of Health and Economy to eliminate trachoma. The participating institutions were the National Autonomous University of Mexico, the Metropolitan Autonomous University, the Iberoamerican University, and the Anáhuac University, as well as the Secretariates of Health and Education of the State, and numerous private companies. ${ }^{5}$

For active trachoma infections, WHO recommends the use of tetracycline in $1 \%$ ophthalmic ointment and azithromycin $20 \mathrm{mg} / \mathrm{kg}$ weight. However, in the historic endemic area of the Chiapas state, the use of tetracycline was initially ruled out by a lack of compliance by the population, mainly because of the prolonged treatment course (of six weeks) and the unpleasant side effects reported by patients. As a result, PEPCT opted for azithromycin, given in in a single dose, which was well tolerated by adults as well as children. Treatments were only prescribed through azithromycin and active phase patient registration. Children under 6 months of age, were excluded and no other antibiotics were used. ${ }^{5}$

In order to interrupt the transmission of C. trachomatis, the program implemented from the outset activities that promoted facial hygiene. The promotion of facial hygiene, the use of latrines, water, and clean patio and household was effected through educational materials, guides and posters (some in local languages) aimed at health personnel, promoters and municipality committees.

During 2010, the PEPCT brigades re-evaluated facial hygiene in 43,026 children under the age of 11 in the five municipalities of the historic endemic area. Of these, 41,896 children met the clean-face criterion, representing $97.37 \%$. of the population evaluated. This was $1.37 \%$ more than that during 2005; 1130 children exhibited poor facial hygiene, the most common signs being discharge from the eyes, nose, dirty with grime, and others (food scraps). The 2011 evaluation found that out of 47,666 children under the age of 11 examined from these municipalities, 46,995 children $(98,59 \%)$ met the clean face criterion, an increase of $1.22 \%$ compared to the previous year. ${ }^{5}$

From 2000 to the present, home-to-home searches have also been carried out in the five municipalities endemic for trachoma, to detect cases of trachoma and to offer surgery when appropriate. From 2002 to 2004, 236 TT cases were detected, of which 228 (97\%) were surgically corrected. The municipality with the highest number of surgeries was the municipality of Oxchuc (158 surgeries) followed by San Juan Cancuc (33 surgeries); behind them were the municipalities of Tenejapa, Chanal, and Huixtán. By 2005, 249 people were identified and surgically treated. ${ }^{5}$

PEPCT (2004-2010) detected 153 TT cases requiring surgical care, which were carried out continuously in endemic municipalities; however, some of the patients required more than one surgery, mostly reconstructive. The follow-up approach for these recurrent patients was conducted through the health brigades of the trachoma program, which had the effect of generating acceptance and awareness for surgical correction with the team of certified surgeons. ${ }^{5}$

The trachoma program at Chiapas Health Services has maintained the nominal census of patients with a history of trachoma-related surgery since 2004. Each patient has a dossier, which among many other variables includes the name, age, gender, date of surgeries, what type of surgery was performed and the surgeon who performed the operation. For 2015, a total of 146 patients from the five endemic municipalities were recoded: Oxchuc (99), San Juan Cancuc (14), Tenejapa (16), Huixtán (11) and Chanal (6). Of these, 143 patients accepted some form of intervention, but three patients were considered reluctant as they did not agree to move to the closest city to be treated. From 2004 through 2015, 487 interventions were carried out in Oxchuc (301), San Juan Cancuc (50), Tenejapa (56), Huixtán (67), and Chanal (13). Of the 487 
patients involved, 146 had relapsed and those patients are still under supervision by the PEPCT. The 146 relapsing patients were distributed by age group as follows: 24 patients 65 years of age or under, 75 patients from 65 to 79 years old, and 47 patients of 80 years old and over. The most affected sex were females (71\%). As for the increased frequency of interventions in the right or left eye, no significant difference was found. ${ }^{5}$

During the period 2000-2015, the Mexico's Directorate-General for Epidemiology recorded a total of 3868 known cases of trachoma, which $99.37 \%(3,844$ cases) were confirmed and corresponded to the historically endemic focus of the state of Chiapas. The remaining $0.63 \%$ (24 suspected cases) reported by other States did not correspond to trachoma validated by epidemiological research which resulted in an annual average of 240.5 cases/year. It was concluded that trachoma in all its clinical forms had a clear and sustained decrease in Chiapas and in Mexico as a whole. ${ }^{5}$

The former focus has met the trachomatous trichiasis (TT) prevalence indicator for elimination as a public health problem, which is less than one "new" TT case per 1000 inhabitants of total population in the endemic area. In fact, a TT prevalence of zero "new" TT per 1000 inhabitants has been observed since 2005. From 2005 to the present, the communities of municipalities known historically to have trachoma have been monitored twice a year by the certified brigades of the PEPCT. As part of the monitoring program for known and "new" TT cases, the only municipality with a TT prevalence of over 1 "new" TT case per 1000 inhabitants is Oxchuc, while all others maintained a sustained prevalence below $1 / 1000 .^{5}$

From 2015 to the present, all municipalities also recorded a prevalence of less than $1 \%$ of follicular trachomatous inflammation (TF) per children aged 1 to 9 years. This finding was the result of direct household visits that took place, twice per year until 2007 and annually from 2008 to 2014 in the historic endemic municipalities for trachoma. ${ }^{5}$

\section{The CEA of the Trachoma Program}

We estimated that from the period from 2004 to 2020 a total of 151,744 people resided in the five historically endemic communities of Chiapas. A total of $\$ 5,905,878.70$ was spent on the program (Table 3) representing an expenditure of $\$ 38.92$ per person during the entire 17 year period during which the program was operational. $^{33}$

\section{Discussion}

Mexico started the fight against onchocerciasis and trachoma in the $1930 \mathrm{~s},{ }^{36,38,53,54}$ both programs adopted the strategies developed by the WHO/PAHO and has eliminated both scourges of disease in Mexico as public health problems. $^{32,56-62}$

There are still 3.8 million cases of blindness due to onchocerciasis worldwide and 5.3 million cases of low vision, resulting in a potential productivity loss of \$2.9 billion. ${ }^{55}$ Depending on the level of pre-control endemicity, excess mortality accounted for between $29 \%$ and $43 \%$ of the estimated burden of the disability adjusted life years (DALY) prior to control. The elimination of onchocerciasis would have generated billions in economic benefits. ${ }^{55,56}$ During the last 40 years, several onchocerciasis control programs have been implemented. ${ }^{20,32,39,57-}$ ${ }^{60}$ OEPA (2002-present) began in 1992 in six countries in the Americas (serving in 13 discrete foci); ${ }^{61,62}$ of these, four countries have successfully verified elimination (Colombia in 2013, Ecuador in 2014, ${ }^{57}$ Mexico in $2015,{ }^{20}$ and Guatemala in $2016^{58}$ ) using a strategy of supplying ivermectin to endemic countries. Globally, over 7.8 billion ivermectin pills have been donated for the treatment of onchocerciasis and lymphatic filariasis. This unprecedented donation has allowed control of onchocerciasis in endemic areas where vector control was not feasible or too costly to maintain. ${ }^{20,57-59}$

As the number onchocerciasis and trachoma cases in Mexico was zero in 2020 indicating both diseases had been eliminated, we calculated the CEA. The CEA demonstrated how the implementation of the guidelines indicated by the WHO were cost-effective when adopted by government institutions. Early prevention, which is relatively inexpensive, can preclude serious and costly health problems in the long term. ${ }^{60,61}$

Mexico has made large investments in public health programs, and these have resulted in a number of successes, including the elimination of onchocerciasis, trachoma, and rabies; however, few are of these have had a CEA. Here, we analyzed the cost of the OEPA strategy for onchocerciasis elimination in Mexico. The cost of the onchocerciasis elimination program was greatly reduced by the donation of ivermectin by Merck. Mexico used $11,322,643$ doses of ivermectin during its elimination program. The donation of the ivermectin was necessary to treat the eligible population; OEPA was indispensable in this process as they were responsible for arranging for the 
donation of the drug with Merck \& Co. through the Mectizan Donation Programme. In addition, the Mexican program guaranteed, through trained personnel (the brigades), that ivermectin reached the inhabitants of the at risk areas, resulting in a total expenditure of $\$ 57,510,669.73$. Treatment persisted quarterly with coverages over $85 \%$ of eligible population, and this required a high awareness of the authorities and the target population. Currently, ivermectin has ended, but both programs continue with post-treatment monitoring and promotion. ${ }^{32}$

Trachoma is a public health problem in 42 countries and it is responsible for the blindness and visual impairment of nearly 1.9 million people. Nearly 182 million people live in endemic areas. It is hyperendemic in rural, poor, and remote areas of countries in Africa, Asia, South and Central America, Australia, and the Middle East, ${ }^{62-64}$ where an estimated 1.3 million people are blinded by the disease and roughly another 1.8 million suffer from impaired vision. ${ }^{65}$ Countries with known or suspected blinding trachoma have 3.8 million cases of blindness and 5.3 million cases of low vision and a potential productivity loss of $\$ 2.9$ billion. Cases of trachoma induced visual loss have resulted in the los of 39 million DALYs. ${ }^{54,63}$ It is estimated that eliminating trachoma as a public health problem would generate an economic gain of $\$ 102$ billion. $^{64}$ In 2000, it was predicted that, without additional interventions, the overall number of blind people would increase to 76 million in 2020, with trachoma being one of the main infectious causes of preventable blindness.

In Mexico, the SAFE program strategy was adopted as its preferred approach to controlling and eliminating trachoma. ${ }^{66}$ The four components of this strategy are trichiasis surgery, treatment with antibiotics for infections, facial cleansing, and environmental improvements to reduce transmission. ${ }^{62}$ In the Mexican trachoma elimination program, Mexican trained personnel (doctors and nurses) who spoke the mother tongue of the Tzotzil and Tzeltal were employed. The brigade emphasized the four components; they visited the entire population at risk (twice a year), to locate acute cases which were then treated with azithromycin. If a patient with TT was identified, it was managed through surgery free of charge. The brigades also conducted hygiene workshops and collaborated with the local authorities the installation of latrines and drinking water networks.

To our knowledge the cost and benefit of the SAFE programs strategy has not been calculated previously. Using the CEA, we observed that during 17 years, Mexico spent $\$ 5,905,878.70$ representing $\$ 38.92$ per person. This amount is much less than the cost of high-quality surgery in the presence of TT cases. The present information will be useful mainly to the countries of Latin America with evidence of trachoma and blindness caused by trachoma, including Brazil, Colombia, and Guatemala where there are an estimated 5 million people at risk of contracting the disease. ${ }^{67,68}$ For African countries, while conditions are different, the present study can strengthen the need to generate permanent programs with human and financial resources typical of government and health institutions.

The achievement of the onchocerciasis and trachoma programs of Mexico, in addition to being historic, will serve as a precedent for other public health programs. In summary, the present study documented the contributions of multi-sectoral work for the elimination of onchocerciasis and trachoma in Mexico, under the leadership of the National Health System, where we highlighted the importance of public health programs. These programs generated and relied upon reliable, robust data, and considerable monitoring in the implementation of measures or strategies. The programs created information systems that remained over time, the brigades were continuously trained and suffered minimal turnover. There was also a permanent contribution of economic resource before, during, and after achievement of the elimination goal, and it was guided by the advice of experts on the subject and organizations that followed WHO/PAHO guidelines.

\section{Acknowledgments}

We thank the higher health authorities Drs. Jesús Felipe González-Roldan, Fabián Correa Morales, Gustavo SánchezTejeda, and Maria Eugenia Algarra-Orozco of Centro Nacional de Programas Preventivos y Control de Enfermedades (CENAPRECE-Ministry of Health of Mexico) for help guide the study. We are indebted to the personnel of the brigades of the onchocerciasis and trachoma programs (State Secretariate of Health) of Oaxaca and Chiapas, who enthusiastically collaborated in this research to make this study feasible. This document is part of the doctoral research work of Nadia A. Fernández-Santos to fulfill requirements of the Autonomous University of Tamaulipas, Mexico.

\section{Disclosure}

The authors report no conflicts of interest for this work. 


\section{References}

1. González RJ, Cruz-Ortiz N, Rizzo N, et al. Successful interruption of transmission of Onchocerca volvulus in the Escuintla-Guatemala focus, Guatemala. PLoS Negl Trop Dis. 2009;3(3):e404. doi:10.1371/journal.pntd.0000404

2. World Health Organization. Trichiasis Surgery for Trachoma. Update from Final assessment of Trichiasis surgeons and Trichiasis surgery for trachoma, the bilamellar tarsal rotation procedure (WHO/PBL/ 93.29). Geneva; 2013.

3. World Health Organization. Report on the Meeting on post-endemic Surveillance for Blinding Trachoma; 2008. Available from: http://www. w ho.int/b 1 i nd n e s s/p u b 1 i c a t i o n s / MEETINGONTRACHOMASURVEILLANCESYSTEM2008FINALV ERSION.pdf. Accessed October 18, 2021.

4. Secretary of Health of Mexico. Informe del pais oncocercosis en México. Secretaría de salud de méxico/programa nacional para la eliminación de la oncocercosis (PNEO-M) [Onchocerciasis country report in Mexico. Secretary of Health of Mexico/National Program for the Elimination of Onchocerciasis (PNEO-M)]; 2014. Available from: https://www.gob.mx/cms/uploads/attachment/file/390792/ DOSSIER_MEXICO_18_NOVIEMBRE_2014_1.pdf. Accessed September 21, 2021. Spanish.

5. Secretary of Health of Mexico. Expediente del Pais, Eliminación de Tracoma como un Problema de Salud Pública. [Trachoma Country Report in Mexico. Secretary of Health of Mexico]. de Subsecretaría de Prevención y Promoción; 2016. Available from: https://www.gob. $\mathrm{mx} / \mathrm{cms} /$ uploads/attachment/file/390731/DOSSIER_TRACOMA_ MEXICO_2016_OPS_22_ABRIL.pdf. Accessed September 21, 2021.

6. Secretary of Health of Mexico. Programa de Acción Específico Eliminación de la Oncocercosis 2013-2018. de Subsecretaría de Prevención y Promoción; 2013. Available from: http://www.cena p r e c e . s a lud.gob.m x/d e s c a r g a s/pd f/PA E EliminacionOncocercosis2013_2018.pdf. Accessed September 21, 2021.

7. Centers for Disease Control and Prevention. Office of the Associate Director for Policy. Using evaluation to inform CDC's policy process; 2015. Available from: https://www.cdc.gov/policy/analysis/process/ docs/usingevaluationtoinformcdespolicyprocess.pdf. Accessed September 21, 2021.

8. Centers for Disease Control and Prevention; National Center for Injury Prevention and Control. Step by step - evaluating violence and injury prevention policies; 2013. Available from: https://www.cdc.gov/injury/ pdfs/policy/Brief\%201-a.pdf. Accessed September 21, 2021.

9. Margeli Pérez HM, Almeida Niquinga HF. Daño visual y ocular por oncocercosis en México. An Soc Mex Oftal. 1985;59(4):101-126.

10. Avilés Parra S. Batallón en el trópico; 50 hombres en la lucha contra la oncocercosis. Med Rev Mex. 1948;28:114-120.

11. Balanzario I. La oncocercosis y el síndrome epiléptico. Prensa Med Mex. 1942;5:15-42.

12. Barragán Callejas H. Algunas consideraciones sobre la oncocercosis. Med Mex. 1937;17:294-306.

13. Aguirre Beltrán G. La población negra de México: Estudio etnohistórico (2a edition). Fondo de Cultura Económica; 1972.

14. Álvarez Ámezquita J. La oncocercosis como problema de salud pública. Salud Publica Mex. 1962;4:316-319.

15. Barttner FC. Note on distribution of oncocercosis in México. Trop Dis Bull. 1945b;42:649-650.

16. Rodríguez-Pérez MA, Unnasch TR, Domínguez-Vázquez A, et al. Lack of active Onchocerca volvulus transmission in the northern chiapas focus of Mexico. Am J Trop Med Hyg. 2010b;83:15-20. doi:10.4269/ajtmh.2010.09-0626

17. Álvarez Ámezquita J. Avances en oncocercosis. Salud Publica Mex. 1964;6:549-550.
18. Mazzotti Galindo L. Tratamiento de la oncocercosis. Salud Publica Mex. 1962;4:1047-1054.

19. Rodriguez-Perez MA, Unnasch TR, Dominguez-Vazquez A, et al. Interruption of transmission of Onchocerca volvulus in the oaxaca focus, Mexico. Am J Trop Med Hyg. 2010a;83(1):21-27. doi:10.4269/ajtmh.2010.09-0544

20. Rodríguez-Pérez MA, Fernández-Santos NA, Orozco-Algarra ME, et al. Elimination of onchocerciasis from Mexico. PLoS Negl Trop Dis. 2015;9(7):e0003922. doi:10.1371/journal.pntd.0003922

21. Rodriguez-Perez MA, Dominguez-Vazquez A, Unnasch TR, et al. Interruption of transmission of Onchocerca volvulus in the Southern Chiapas Focus, Mexico. PLoS Negl Trop Dis. 2013d;7(3):e2133. doi:10.1371/journal.pntd.0002133

22. Rodríguez-Pérez MA, Sauerbrey M, Hassan HK, et al. Evidence for suppression of Onchocerca volvulus transmission in the oaxaca focus in Mexico. Am J Trop Med Hyg. 2008a;78(1):147-152. doi:10.4269/ajtmh.2008.78.147

23. Martín-Tellaeche A. Oncocercosis. Endemia Rural de los Ríos que Ciega (1875-2008). Bayer Envionmental Science; 2009.

24. Mazzottii GL, Hewitt IR. Tratamiento de la oncocercosis por el cloruro de 1-dietilcar-bamil - 4 -metilpiperazina (hetrazán). Nota Preliminar Med Rev Mex. 1948;28:39-42.

25. Fernández DCJ. La oncocercosis y la campaña antioncocercosa en el Estado de Chiapas. Salud Publica Mex. 1967;13:90.

26. Amorós GR. La oncocercosis es enfermedad profesional. México: Talleres Gráficos de la Nación; 1949: 44.

27. Álvarez Gordillo JG, Rivas Alcalá AR. Modificaciones en los leucocitos periféricos de pacientes oncocercosos tratados con dosis consecutivas de ivermectina. Salud Publica Mex. 1991;2:112-122.

28. Martín Tellaeche A, Mascareño Sauceda F. Oncocercosis. SSA/Dir. Gral. Med. Prev./ISBN 968 811-116; 1990:46-47.

29. Basáñez MG, Ricardez-Esquinca J. Models for the population biology and control of human onchocerciasis. Trends Parasitol. 2001;17 (9):430-438. doi:10.1016/S1471-4922(01)02013-X

30. Pedroza Jurado E, Martínez Trujillo C, Ocampo Lujano Á, Huerta López JG. Evaluación inmunoenzimética de Ig.E sérica en oncocercosos de Chiapas [Immunoenzymatic evaluation of serum IgE in onchocerciasis patients from Chiapas, Mexico]. An Soc Mex Oftalmol. 1989;31:772-778.

31. Ortega Gutierrez M, Oliver CM. Entomología de la oncocercosis en el Soconusco, Chiapas, México; II-Estudio sobre dinámica de población de las tres especies de simúlidos considerados transmisores de oncocercosis en el foco sur de Chiapas. In: Folia Entomológica Mexico. 1985;66:119-136.

32. Fernández-Santos NA, Unnasch TR, Rodríguez-Luna IC, et al. Postelimination surveillance in formerly onchocerciasis endemic focus in Southern Mexico. PLoS Negl Trop Dis. 2020;14(1):e0008008. doi:10.1371/journal.pntd.0008008

33. Frew E. Applied Methods of Cost-Benefit Analysis in Health Care. Oxford University Press. Vol. 4; 2010.

34. Torroella JJ, Portillo C. Hallazgo en una zona en el estado de Chiapas con enfermos tracomatosos. An Soc Mex Oftalmol. 1965;3:161-168.

35. Ochoa-Díaz-López H. Salud, agua y saneamiento para disminuir la prevalencia de tracoma. In: Mejoramiento de las condiciones ambientales y de salud en las comunidades indígenas. San Cristóbal de las Casas, Chiapas:Coordinación Nacional del Seguro Popular de Salud, Coordinación de Salud para Pueblos Indígenas; 2004. Proyecto Conjunto

36. Torroella JJ, Portillo C. Trachoma in the Republic of Mexico. Rev Int Trach Pathol Ocul Trop Subtrop Sante Publique. 1983;21:59-65.

37. Lutzow-Steiner M. Prevalencia y factores asociados al tracoma en 17 localidades de la zona endémica de Chiapas, agosto de 2002 a julio de 2003. Tesis de Especialidad en Epidemiologia. Facultad de Medicina UNAM; Septiembre 2003.

38. Ontiveros-Caso P. El tracoma en México. Tesis de licenciatura. México, DF: Facultad de Medicina UNAM; 1943.

39. World Health Organization. Making progress towards the global elimination of blinding trachoma. 11th Meeting of GET2020 Report. Geneva, Switzerland; 2007. 
40. Fabiola HP. Tracoma. Antecedentes históricos. Instituto de Salud del Estado de Chiapas. Available from: https://www.imbiomed.com.mx/ articulo.php?id=100483. Accessed September 21, 2021.

41. Lorenzo C. Trachoma. Public Health Pap Rep. 1906;32(1):230-237. PMCID: PMC2222462.

42. García-Villegas H, Pérezares-Ruiz J, Castrillón-Rivera L, AcevesPastrana P, Lobato-Diaz E. El Tracoma. Asociación Mexicana de Salud y Economía; 2009.

43. Bernarda ZR. Diagnóstico y frecuencia de tracoma en Chiapas [Bachelor's thesis]. México, DF: Facultad de Medicina UNAM; 1985.

44. Wilson M, Keyvan-Larijani E, Millán-Velasco F, Tielsch JM, Taylor HR. The epidemiology of trachoma in Chiapas (México) Rev Int Trach Pathol Ocul Trop Subtrop Sante Publique. 1987;64: 159-174.

45. Salvatierra B, Estrada R, Torres G, et al. Pobreza y tracoma en los Altos de Chiapas. In: Pobreza y salud: Los retos de la investigación en Chiapas. Tapachula: UNACH-ECOSUR. 1997:22-25.

46. Ochoa-Díaz-López H. Hacia la eliminación del tracoma como causa de ceguera en Chiapas. In: Dossier PAHO: ME/CNT/1100073.001. 2011:44.

47. Ramírez-Ortiz MA, Rodríguez-Almaraz $\mathrm{M}$, Ochoa $\mathrm{H}$, et al. Randomised equivalency trial comparing $2.5 \%$ povidone iodine eye drops and ophthalmic chloramphenicol for preventing neonatal conjunctivitis in a trachoma endemic area in southern Mexico. $\mathrm{Br}$ J Ophthalmol. 2007;91(11):1430-1434. doi:10.1136/bjo.2007.119867

48. Vélez DM, Chavira RA. Distribución geográfica del tracoma en México. An Soc Mex Oftalmol. 1923;IV:109-113.

49. Kumate J. La transición epidemiológica del siglo XX: ¿vino nuevo en odres viejos? Rev Fac UNAM. 2002;45(3):97-102.

50. Goldschmidt P, Vanzzini Zago V, Diaz Vargas L, et al. Chlamydia trachomatis in the conjunctiva of children living in three rural areas in Mexico. Rev Panam Salud Pública. 2007;22(1):29-34. doi:10.1590/S1020-49892007000600004

51. Taylor HR, Velasco FM, Muñoz EC, Ruvalcaba AM, Greene BM. Trachoma in Chiapas, Mexico. Rev Int Trach Pathol Ocul Trop Subtrop Sante Publique. 1983;60:17-27.

52. Mas-Oliva J, García-Villegas H, Huerta L. Respalda la Universidad campaña contra el tracoma. Gaceta UNAM. 2007;3954:8.

53. Beltrán Hernández F, Gómez Priego A, Martínez Chacón JF, OrtegaGutiérrez M. Perspectivas actuales para la vigilancia epidemiológica de la oncocercosis en México. Salud Publica Mex. 1979;XXI (6):771-785.

54. Frick KD, Lietman TM, Holm SO, Jha HC, Chaudhary JSP, Bhatta RC. Cost-effectiveness of trachoma control measures: comparing targeted household treatment and mass treatment of children. Bull World Health Organ. 2001;79:201-207.
55. Turner HC, Walker M, Pion SD, McFarland DA, Bundy DA, Basáñez MG. Economic evaluations of onchocerciasis interventions: a systematic review and research needs. Trop Med Int Health. 2019;24(7):788-816. doi:10.1111/tmi.13241

56. Basu J, Friedman B, Burstin H. Primary care, HMO enrollment, and hospitalization for ambulatory care sensitive conditions: a new approach. Med Care. 2002;40(12):1260-1269. doi:10.1097/000056 50-200212000-00013

57. Guevara Á, Lovato R, Proaño R, et al. Elimination of onchocerciasis in Ecuador: findings of post-treatment surveillance. Parasit Vectors. 2018;11(1):1-8. doi:10.1186/s13071-018-2851-3

58. Richards F Jr, Rizzo N, Espinoza CED, et al. One hundred years after its discovery in Guatemala by Rodolfo Robles, Onchocerca volvulus transmission has been eliminated from the central endemic zone. Am J Trop Med Hyg. 2015;93(6):1295-1304. doi:10.4269/ajtmh.15-0364

59. Gold MR, Siegel JE, Russell LB, Weinstein MC. Cost- Effectiveness in Health and Medicine. New York: Oxford University Press; 1996.

60. Liljas B. How to calculate indirect costs in economic evaluations. Pharmacoeconomics. 1998;13(1):1-7. doi:10.2165/00019053-19981 3010-00001

61. Koopmanschap MA, Rutten FF, van Ineveld BM, van Roijen L. The friction cost method for measuring indirect costs of disease. $J$ Health Econ. 1995;14(2):171-189. doi:10.1016/0167-6296(94)00044-5

62. Negrel AD, Mariotti SP. WHO alliance for the global elimination of blinding trachoma and the potential use of azithromycin. Int $J$ Antimicrob Agents. 1998;10(4):259-262. doi:10.1016/S09248579(98)00046-6

63. Burton MJ, Mabey DC. The global burden of trachoma: a review. PLoS Negl Trop Dis. 2009;3(10):e460. doi:10.1371/journal.pntd.0000460

64. Polack S, Brooker S, Kuper H, et al. Mapping the global distribution of trachoma. Bull World Health Organ. 2005;83:913-919.

65. Resnikoff S, Pascolini D, Etya'ale D, et al. Global data on visual impairment in the year 2002. Bull World Health Organ. 2004;82:844-851.

66. Pan American Health Organization; World Health Organization. Trachoma; 2019. Available from: https:/www.paho.org/en/topics/tra choma. Accessed September 21, 2021.

67. Pan American Health Organization; World Health Organization. CD53.R14: Estrategia para el Acceso Universal a la Salud y la Cobertura Universal de Salud [CD53.R14: Strategy for universal access to health and universal health coverages]; 2014. Available from: https://iris.paho.org/handle/10665.2/7652. Accessed September 21, 2021

68. World Health Organization. Trachoma Control. A Guide for Programme Managers. ISBN 924154690 5. Geneva: World Health Organization; 2006.
Research and Reports in Tropical Medicine

\section{Publish your work in this journal}

Research and Reports in Tropical Medicine is an international, peerreviewed, open access journal publishing original research, case reports, editorials, reviews and commentaries on all areas of tropical medicine, including: Diseases and medicine in tropical regions; Entomology; Epidemiology; Health economics issues; Infectious disease; Laboratory science and new technology in tropical medicine;
Parasitology; Public health medicine/health care policy in tropical regions; and Microbiology. The manuscript management system is completely online and includes a very quick and fair peer-review system. Visit http://www.dovepress.com/testimonials.php to read real quotes from published authors. 